\title{
WORKSHOP STRATEGI PENINGKATAN POPULARITAS KONTEN SERTA MENJAGA KEAMANAN DATA PRIBADI DI BERBAGAI PLATFORM MEDIA SOSIAL
}

\author{
Siti Alvi Sholikhatin'1), Wanda Fitrianingsih2), Sahira Dhiyaulhaq ${ }^{2)}$ \\ 1)Program Studi Informatika, Fakultas IImu Komputer, Universitas Amikom Purwokerto, Purwokerto, Jawa Tengah, Indonesia \\ 2) Program Studi Bisnis Digital, Fakultas Bisnis dan IImu Sosial, Universitas Amikom Purwokerto, Purwokerto, Jawa Tengah, \\ Indonesia \\ Corresponding author : Siti Alvi Sholikhatin \\ E-mail : sitialvi@amikompurwokerto.ac.id
}

Diterima 16 September 2020, Direvisi 30 September 2020, Disetujui 01 Oktober 2020

\begin{abstract}
ABSTRAK
Media sosial telah merubah gaya hidup masyarakat di era digital yang perkembangannya kini semakin pesat. Media sosial dimanfaatkan oleh masyarakat di berbagai bidang kehidupan, tak terkecuali di bidang pendidikan. Penggunaan media sosial selain untuk mendukung kegiatan belajar mengajar, juga sebagai media promosi institusi tersebut kepada masyarakat luas. Popularitas media sosial mempengaruhi rating dan bagaimana seseorang menciptakan branding untuk diri mereka. Oleh karena itu, diperlukan strategi yang efektif agar media sosial yang digunakan dapat memberikan manfaat yang optimal. Aspek lain yang tak kalah penting adalah menjaga keamanan informasi data diri seseorang di akun media sosial. Oleh sebab itu, pengetahuan untuk meningkatkan kesadaran diri akan pentingnya menjaga keamanan informasi data diri perlu terus digalakkan, terutama di kalangan guru yang menjadi penggiat media sosial baik untuk kepentingan pribadi maupun institusi. Menjawab kebutuhan tersebut, maka diadakan workshop tentang keamanan data diri dan konten media sosial. Tujuan diadakannya workshop ini adalah untuk menumbuhkan kesadaran akan pentingnya menjaga keamanan data pribadi sekaligus mempelajari strategi tentang peningkatan popularitas konten di media sosial. Metode yang digunakan dalam pelaksanaan workshop ini adalah dengan penyampaian materi dalam bentuk ceramah hasil dari pengabdian kepada masyarakat ini yaitu sebanyak 90\% guru di SMP Negeri 3 Purbalingga menilai bahwa workshop ini sangat bermanfaat untuk menambah pengetahuan dan meningkatkan kesadaran dalam menjaga data pribadi di akun media sosial.
\end{abstract}

Kata kunci: pengabdian masyarakat; workshop; media sosial; keamanan; data pribadi.

\begin{abstract}
Social media has changed the lifestyle of people in the digital era. Social media is used in various fields, including education. The use of social media is not only to support the teaching process and learning activities, but also to promote the institution to the wider community. The popularity of social media influences rating and how a person creates branding for themselves. Therefore, an effective strategy is needed so that the social media can provide optimal benefits. Another aspect that is also important is the security of personal data on social media accounts. Thus, knowledge to increase self-awareness of the importance of maintaining the security of personal data information needs to be continuously promoted, especially among teachers who are social media activists for both personal and institutional interests. Responding to the need, workshop about privacy security and social media content was held. This workshop is conducted with the main goal is to raise the awareness of privacy security and strategic ways to improve popularity in social media. The method used in this workshop is a lecture performed in front of the audience, and the result shows as many as $90 \%$ of teachers at SMP Negeri 3 Purbalingga considered this workshop is useful to increase knowledge and awareness in maintaining personal data on social media accounts.
\end{abstract}

Keywords: community service; workshop; social media; security; personal data.

\section{PENDAHULUAN}

Institusi pendidikan merupakan salah satu ranah yang tak luput dari serangan perkembangan teknologi informasi dan komunikasi, yang dimanfaatkan untuk kebutuhan formal dan informal. Teknologi yang paling banyak mendapat sorotan dan populer digunakan yaitu media sosial dari berbagai platform. Penggunaan media sosial selain untuk mendukung kegiatan belajar mengajar, 
seperti menginformasikan pengumuman terkait kegiatan belajar mengajar internal, juga sebagai media promosi institusi tersebut kepada masyarakat luas. Yang dimaksud media sosial menurut Shirky yang dikutip oleh (Rahayu \& Laela, 2018) adalah merupakan alat untuk meningkatkan kemampuan pengguna untuk berbagi (to share), bekerja sama (to cooperate) diantara pengguna dan melakukan tindakan secara kolektif yang semuanya berada di kerangka institusional maupun organisasi. Selain untuk saling berbagi dan bekerja sama, media sosial juga dimanfaatkan oleh individu atau kelompok untuk saling berkomunikasi, berkolaborasi, dan bermain dalam satu komunitas.

Menurut (Sindang, 2013) media sosial secara umum dikelompokkan menjadi tujuh: 1) berbentuk jejaring sosial, 2) berbentuk blog, 3) berbentuk wiki, 4) berbentuk podcast, 5) berbentuk forum, 6) berbentuk komunitas konten, dan 7) berbentuk microblogging. Setiap jenis media sosial tersebut digunakan oleh masyarakat untuk berbagai kebutuhan yang berbeda, misalnya untuk pemasaran atau promosi barang dan jasa secara online, menginformasikan pengumuman kepada masyarakat, dan sebagai self-branding. Bahkan beberapa media sosial sekarang telah dimanfaatkan secara positif dan masif sebagai media dakwah yang cukup efektif untuk menjangkau seluruh lapisan masyarakat. Data ini salah satunya diambil dari penelitian (Ahmad Fathan Hidayatullah, 2016) yang menyatakan sekitar $68 \%$ dari pengguna media sosial Twitter mem-follow akun dakwah dan mengikuti kontennya.

Media sosial telah dimanfaatkan di berbagai bidang kehidupan dan memberi efek positif serta negatif secara signifikan. Dampak positif seperti seperti diungkapkan oleh (Siswanto, 2018) yang memanfaatkan media sosial untuk membantu Usaha Kecil Menengah (UKM) dalam memasarkan produknya. Di bidang pemerintahan pun telah memanfaatkan media sosial terutama Facebook sebagai sarana komunikasi antara pemerintah dan masyarakat (Izzati et al., 2018). Facebook juga merupakan salah satu media sosial yang efektif untuk membangun popularitas suatu merk tertentu, seperti penelitian yang dilakukan oleh (Hanifawati et al., 2019). Bahkan media sosial juga digunakan untuk media kampanye sehingga meningkatkan popularitas suatu partai politik pada masa pemilihan umum (Junaidi et al., 2015). Efek lain dari media sosial yaitu, mempengaruhi budaya berbelanja masyarakat, hal ini didukung oleh penelitian yang dilakukan oleh (Andriany \& Arda, 2019) bahwa media sosial mempengaruhi impulse buying sebesar $70 \%$.

Studi lain menunjukkan bahwa penggunaan media sosial selain untuk tujuantujuan di atas, juga sebagai sarana eksistensi diri, media pamer, serta media untuk berinteraksi (Rorimpandey, 2016). Di sisi lain dampak negatifnya pun tak kalah penting untuk diperhatikan. Informasi data pribadi yang kita gunakan pada akun media sosial kita yang tersimpan di internet atau cloud, sangat mungkin untuk diretas dan disalahgunakan. Kejahatan di dunia maya atau yang biasa disebut cyber crime menurut (Ali, 2012) adalah perbuatan melawan hukum yang dilakukan dengan memakai jaringan komputer sebagai sarana/alat atau komputer sebagai objek, baik untuk memperoleh keuntungan ataupun tidak, dengan merugikan pihak lain. Karena itu, kewaspadaan diri dan kehati-hatian perlu terus ditingkatkan agar kita tidak ceroboh membagikan data pribadi yang sensitif di internet yang berpotensi untuk disalahgunakan oleh pihak yang tidak bertanggung jawab.

Workshop atau pelatihan ini bertujuan untuk menangani dua sisi permasalahan dalam bermedia sosial. Yang pertama yaitu memberikan pengetahuan tentang cara-cara efektif dalam meningkatkan popularitas konten dalam bermedia sosial sehingga bisa semaksimal mungkin meningkatkan branding diri, serta cara-cara untuk melindungi data dan informasi di media sosial sehingga terhindar dari cybercrime. Mengapa sasaran atau target utama penulis adalah para guru di SMP Negeri 3 Purbalingga? Ini dikarenakan para guru yang notabene berusia rata-rata 40 tahun keatas, yang disebut sebagai baby boomer, membutuhkan arahan yang tepat agar mampu memanfaatkan media sosial secara bijak dan sesuai dengan porsinya. Dikarenakan, kelompok baby boomer ini bisa dikatakan terlambat mengenal teknologi yang perkembangannya sangat pesat. Jika tidak mendapat informasi bagaimana memanfaatkan teknologi tersebut dengan baik dan benar, dalam hal ini media sosial, maka dikhawatirkan akan terjadi penyalahgunaan media sosial, misalnya menyebarkan berita yang belum terbukti kebenarannya, atau menyebarkan informasi pribadi secara berlebihan.

\section{METODE}

Metode pelaksanaan pengabdian kepada masyarakat ini adalah Metode Seminar yaitu pemateri memberikan ceramah mengenai tata cara dan strategi dalam meningkatkan rating atau popularitas konten di media sosial, serta bagaimana menjaga keamanan data dan informasi pribadi kita di media sosial agar 
terhindar dari kejahatan cyber. Interaksi dengan para guru yang menjadi participant dilakukan dengan metode tanya jawab dan komunikasi dua arah sehingga peserta memahami betul bagaimana meningkatkan rating dan branding diri di media sosial serta menjaga keamanan informasi data pribadi di akun media sosial tersebut.

Alur kegiatan dapat dilihat pada Gambar 1.

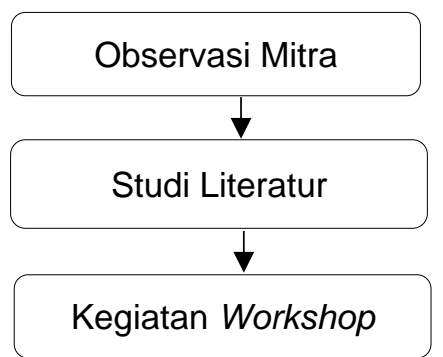

Gambar 1. Alur kegiatan workshop

\section{Deskripsi Gambar 1.}

Observasi mitra

Menentukan tempat kegiatan dan melakukan observasi kebutuhan mitra, dimana para guru di SMP Negeri 3 Purbalingga tergolong awam dalam hal menjaga keamanan data pribadi dan bagaimana meningkatkan popularitas konten di media sosial. Jumlah guru yang berpartisipasi dalam workshop ini adalah 35 orang.

\section{Studi Literatur}

Mencari dan mengumpulkan literatur yang relevan untuk mendukung kegiatan workshop.

Kegiatan Workshop

Pelaksanaan workshop melibatkan seluruh guru di SMP Negeri 3 Purbalingga dengan memberikan pemaparan mengenai strategi meningkatkan popularitas konten dan cara untuk mengamankan data pribadi di berbagai akun media sosial.

\section{HASIL DAN PEMBAHASAN}

Branding di sosial media dipengaruhi kreatifitas konten, dan sharing konten yang menarik sangat potensial untuk meningkatkan jumlah pengikut (Hanifawati et al., 2019). Jumlah pengikut memang tidak bisa menjadi satu-satunya tolok ukur popularitas suatu akun, akan tetapi jumlah pengikut erat kaitannya dengan bagaimana seseorang membangun image dirinya di dunia maya serta meningkatkan faktor trust kepada khalayak. Workshop ini disampaikan dalam bentuk ceramah interaktif yang diikuti oleh 40 guru di SMP Negeri 3 Purbalingga. Pada saat pemaparan materi, para guru antusias menyimak pemaparan materi yang disajikan dengan menarik, presentasi menggunakan infografis yang mudah dipahami, serta materi ini merupakan pengetahuan baru bagi sebagian guru.

Materi pembuka yaitu infografis mengenai perkembangan internet dan jumlah pengguna media sosial di Indonesia, seperti terlihat pada Gambar 2. Berdasarkan data yang dikutip dari (W. A. S. Inc., 2020) dan (H. Inc, 2020) menyatakan bahwa pengguna internet di Indonesia per Januari 2020 adalah sebanyak 175 juta pengguna aktif, sedangkan total 150 juta adalah pengguna media sosial. Rating media sosial yang paling banyak digunakan yaitu: 1) YouTube, 2) WhatsApp, 3) Facebook, 4) Instagram, dan 5) Line. Menurut data tersebut, dapat disimpulkan bahwa media sosial telah menjadi bagian dari kehidupan sehari-hari masyarakat Indonesia dan secara langsung maupun tidak langsung telah mempengaruhi gaya hidup baik secara individu maupun sosial.

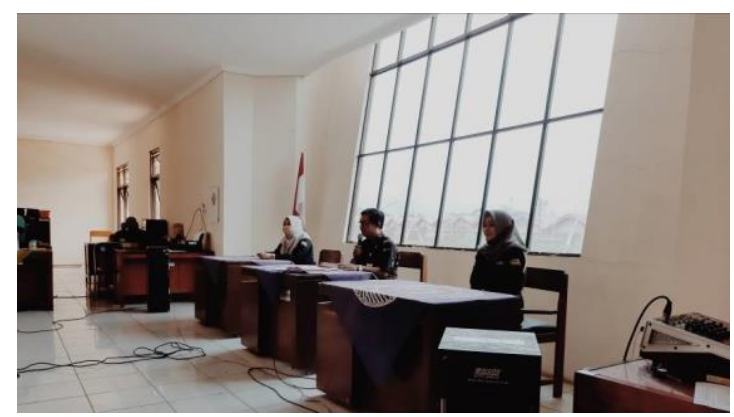

Gambar 2. Kegiatan workshop

Kemudian bagaimana strategi untuk meningkatkan popularitas konten di media sosial? Berdasarkan survei yang dilakukan oleh (H. Inc, 2020) didapatkan data yang berisikan waktu-waktu tertentu yang tepat untuk mengunggah dan berbagi di media sosial. Detail dapat dilihat di Tabel 1.

Tabel 1. Waktu yang tepat untuk unggah di media sosial

\begin{tabular}{clc}
\hline $\begin{array}{c}\text { Media } \\
\text { Sosial }\end{array}$ & \multicolumn{1}{c}{ Hari } & Jam \\
\hline YouTube & Kamis dan & $09.00-11.00$ \\
& $\begin{array}{l}\text { Jumat } \\
\text { Sabtu dan }\end{array}$ & $12.00-16.00$ \\
& Minggu & \\
Instagram & Senin, Rabu, & $11.00-13.00$ \\
& dan Kamis & $19.00-21.00$ \\
Facebook & Kamis, Jumat, & $13.00-16.00$ \\
& Sabtu, dan & \\
& Minggu \\
Twitter & Senin sampai & $12.00-13.00$ \\
& Jumat & \\
\hline
\end{tabular}

Sedangkan waktu paling tidak dianjurkan untuk unggah di Twitter dan Instagram yaitu pada hari Minggu karena engagement pada 
saat akhir pekan cenderung rendah, lalu untuk Facebook waktu yang paling tidak dianjurkan untuk unggah yaitu pada hari Selasa dengan alasan yang sama. Para guru di SMP Negeri 3 Purbalingga sangat tertarik dengan informasi yang disampaikan karena mayoritas belum mengetahui adanya hasil analisis mengenai waktu-waktu terbaik untuk berbagi di media sosial.

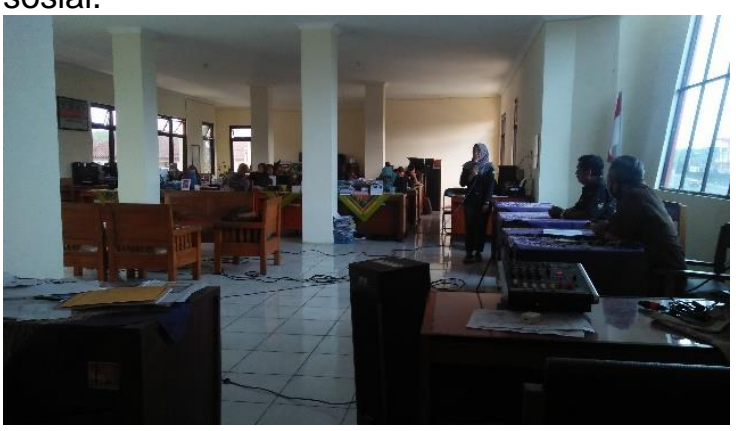

Gambar 3. Pemaparan materi workshop

Pada Gambar 3. menunjukkan pemaparan materi kedua yang tidak kalah penting yaitu mengenai keamanan data pribadi di berbagai akun media sosial. Dari sesi tanya jawab, dapat disimpulkan bahwa 95\% guru belum memiliki kesadaran akan pentingnya menjaga keamanan informasi dan data pribadi di akun media sosial. Antara lain, belum mengatur privacy setting di aplikasi media sosial, belum mengganti password akun media sosial secara berkala, dan belum menerapkan mode two-step verification. Kelengahan dalam menjaga keamanan data pribadi di akun media sosial yang cenderung diabaikan tersebut berpotensi menimbulkan kerugian antara lain bocornya data sehingga digunakan oleh pihak-pihak yang tidak bertanggung jawab untuk melakukan kejahatancyber.

Mengapa kegiatan media sosial kita harus dipastikan keamanannya? Karena menurut informasi dari (Group, 2020), Indonesia menjadi salah satu kontributor terbesar sebagai pencetus serangancyber, dan media sosial menjadi salah satu celah terbesar karena kelancaran konektivitas yang memudahkan penjahat siber untuk melakukan serangan otomatis secara teroganisir dalam skala besar. Hal ini pun berdampak pada maraknya penipuan online yang juga merupakan salah satu efek negatif dari berkembangnya sistem ekonomi digital. Oleh karena itu, menggunakan media sosial dengan bijak dan aman merupakan langkah preventif agar terhindar dari kejahatancyber.

Lalu bagaimana langkah-langkah untuk mengamankan data pribadi dan informasi di media sosial? Langkah-langkah yang bisa dilakukan antara lain: lebih baik menggunakan fitur private account, mengganti password secara berkala, selalu berfikir ulang saat akan membagi apapun di media sosial, berhati-hati saat belanja online, terapkan penyaringan konten, bijak dalam membuat konten dan perhatikan hak cipta, serta matikan permission aplikasi yang tidak perlu. Jika sudah menerapkan langkah-langkah antisipatif seperti di atas, maka kita sudah melakukan usaha yang maksimal dalam menjaga keamanan data dan informasi pribadi dalam bermedia sosial.

Pada saat akhir sesi penyampaian materi, dibagikan kuesioner secara online kepada para guru mengenai kesan dan pesan mengenai workshop yang telah dilakukan. Berdasarkan hasil dari kuesioner tersebut, disimpulkan bahwa 90\% guru berpendapat workshop ini penting untuk meningkatkan kesadaran akan pentingnya menjaga keamanan informasi dan data diri di berbagai akun media sosial, dan diharapkan kegiatan serupa lebih sering dilakukan sehingga informasi penting ini bisa tersampaikan ke masyarakat.

\section{SIMPULAN DAN SARAN}

Media sosial telah mengubah perspektif kehidupan di masyarakat. Akses informasi dan komunikasi secara digital menjadi sangat mudah dilakukan, jarak dan waktu bukan merupakan suatu penghalang. Selain itu, media sosial menjadi alat yang efektif untuk meningkatkan branding diri, baik secara individu ataupun organisasi, sehingga daya saing dan popularitas menjadi maksimal. Menaikkan popularitas dan self-branding sangat penting jika ingin media sosial kita mendapatkan rate dan view yang signifikan. Selain meningkatkan portofilio diri, menjaga data dan informasi pribadi juga harus diperhatikan. Jangan sampai, popularitas yang kita raih menjadikan kita tidak bijak dalam berbagi informasi di internet atau bahkan menyalahgunakan informasi pihak lain untuk kepentingan pribadi.

Workshop yang dilakukan menjadi langkah awal untuk meningkatkan popularitas konten dengan memperhatikan waktu-waktu yang potensial mendapatkan view yang tinggi, serta meningkatkan kesadaran akan pentingnya mengamankan data pribadi di akun media sosial. Hasil dari kegiatan pengabdian kepada masyarakat ini sudah sesuai harapan, yaitu responden yang merupakan para guru di SMP Negeri 3 Purbalingga menyampaikan antusiasmenya, menyatakan bahwa workshop ini membagikan pengetahuan yang penting dan berharap bahwa pelatihan yang sama juga dilakukan lebih sering dan menjangkau responden yang lebih luas. 


\section{UCAPAN TERIMAKASIH}

Terima kasih kepada Universitas Amikom Purwokerto terutama Lembaga Penelitian dan Pengabdian kepada Masyarakat, serta SMP Negeri 3 Purbalingga yang telah membantu secara moril maupun materiil dalam pelaksanaan workshop ini.

\section{DAFTAR RUJUKAN}

Ahmad Fathan Hidayatullah. (2016). Twitter Sebagai Media Dakwah. Teknoin, 22(1), 38-43.

Ali, I. (2012). Kejahatan Terhadap Informasi (Cybercrime) Dalam Konteks Perpustakaan Digital. Visi Pustaka, 14(1), 32-38.

Andriany, D., \& Arda, M. (2019). Pengaruh Media Sosial Terhadap Impulse Buying Pada Generasi Millenial. Festival Riset IImiah Manajemen \& Akuntansi, 6681, 428-432.

Group, K. G. D. (2020). Kompas.com. https://tekno.kompas.com/read/2016/09/3 0/17120067/kenapa.banyak.serangan.cy ber.dari.indonesia.?page $=$ all

Hanifawati, T., Ritonga, U. S., \& Puspitasari, E. E. (2019). Popularitas Merek di Sosial Media: Analisis Pengaruh Waktu, Konten, dan Interaksi Merek. Esensi: Jurnal Bisnis Dan Manajemen, 9(1), 9-26. https://doi.org/10.15408/ess.v9i1.9037

Inc., W. A. S. (2020). We Are Social. https://wearesocial.com/

Inc, H. (2020). Social is your superpower. https://hootsuite.com/id/

Izzati, A. N., Pratama, A., Aristamy, I. M., Najwa, N. F., \& Rakhmawati, N. A. (2018). KATEGORISASI JENIS INTERAKSI PEMERINTAH DAN MASYARAKAT SERTA POPULARITAS MEDIA SOSIAL PEMERINTAH DAERAH. Jurnal Sistem Informasi, 14(1), 1-8.

Junaidi, J., Alfiah, F., Susanti, E., Kristinna, J., Ardiansyah, O. R., \& Pradipta, D. (2015). Manfaat Menganalisis Pengaruh Sosial Media Facebook Terhadap Kampanye Politik Di Indonesia. Seminar NasionalTeknologilnformasidan

Multimedia,

6-8. https://www.ojs.amikom.ac.id/index.php/s emnasteknomedia/article/download/1020/ 982

Rahayu, E. S., \& Laela, S. (2018). Pengaruh Minat Berwirausaha Dan Penggunaan Sosial Media Terhadap Kewirausahaan Mahasiswa. Jurnal Pengembangan Wiraswasta, 20(3), 203. https://doi.org/10.33370/jpw.v20i3.246

Rorimpandey, P. A. (2016). Perilaku Komunikasi Mahasiswa Pengguna Sosial
Media Path (Studi Pada Mahasiswa IImu Komunikasi Fisip Universitas Sam Ratulangi). Acta Diurna, 5(3), 1-5.

Sindang, E. (2013). Manfaat Media Sosial Dalam Ranah Pendidikan dan Pelatihan. Pusdiklat KNPK, $1-8$.

Siswanto, T. (2018). Optimalisasi Sosial Media Sebagai Media Pemasaran Usaha Kecil Menengah. Liquidity, 2(1), 80-86. https://doi.org/10.32546/lq.v2i1.134 